\title{
Adherence of pain assessment to the German national standard for pain management in 12 nursing homes
}

\author{
Jürgen Osterbrink PhD MN(HP) DHL(hc) RN, Zsuzsa Bauer PhD, Barbara Mitterlehner Magistra MPH, \\ Irmela Gnass MScN, Patrick Kutschar Magister
}

J Osterbrink, Z Bauer, B Mitterlehner, I Gnass, P Kutschar. Adherence of pain assessment to the German national standard for pain management in 12 nursing homes. Pain Res Manag 2014;19(3):133-140.

BACKGROUND: Pain is very common among nursing home residents. The assessment of pain is a prerequisite for effective multiprofessional pain management. Within the framework of the German health services research project, 'Action Alliance Pain-Free City Muenster', the authors investigated pain assessment adherence according to the German national Expert Standard for Pain Management in Nursing, which is a general standard applicable to all chronic/acute pain-affected persons and highly recommended for practice.

OBJECTIVES: To evaluate the state of pain assessment and to identify need for improvement in 12 nursing homes in a German city.

METHODS: In the present study, the authors used an ex-post-facto design (survey methodology). Available written policies for routine pain assessment in residents $\geq 65$ years of age were reviewed and a standardized online survey completed by 151 of 349 nurses in 12 nursing home facilities was conducted between September 2010 and April 2011.

RESULTS: Most of the included nursing homes provided written policies for pain assessment, and the majority of nurses reported that they assess and regularly reassess pain. However, observational tools for residents with severe cognitive impairment and written reassessment schedules were lacking in many facilities or were inconsistent.

CONCLUSIONS: Essentially, pain assessment appeared to be feasible in the majority of the German nursing homes studied. However, the absence or inconsistency of reassessment schedules indicate that pain management guidelines should include a detailed and explicit reassessment schedule for the heterogenic needs of nursing home residents. For residents with severe cognitive impairment, assessment tools are needed that are simple to use and clearly indicate the presence or absence of pain.

Key Words: Dementia; Nursing homes; Observational pain tools; Pain measurement; Quality of health care

$\mathrm{T}$ ypically, the vast majority of nursing home $(\mathrm{NH})$ residents experience a variety of acute and chronic medical conditions, such as arthritis, fractures, musculoskeletal conditions, ulcers or neoplasms, that are often associated with pain (1-3). According to international studies, depending on research methods and data sources, up to $80 \%$ of residents in nursing homes are affected by pain (4-6).

Adequate assessment of pain is a prerequisite for an effective multiprofessional pain management (7). However, in NHs, the assessment of pain is a particular challenge because many older adults do not automatically report their pain. They often assume that pain is common for their age and must be endured (8). Assessing pain in NHs is also made more difficult by the fact that a considerable number of residents are incapable of self-reporting their pain. Approximately $60 \%$ of the residents in German NHs have dementia (9). As dementia progresses, the ability of this group of patients to self-report declines rapidly $(10,11)$. Among individuals with limited ability to communicate, it is especially important to systematize and standardize the
Le respect de la norme nationale allemande pour évaluer la douleur dans la gestion de la douleur au sein de 12 foyers pour personnes âgées

HISTORIQUE : La douleur est très courante chez les habitants de foyer pour personnes âgées. Dans un milieu multiprofessionnel, il faut l'évaluer pour la prendre en charge avec efficacité. Dans le cadre du projet de recherche sur les services de santé allemands, intitulé Alliance action sans douleur de la ville de Muenster, les auteurs ont examiné le respect de l'évaluation de la douleur conformément à la norme nationale des experts allemands pour gérer la douleur en soins infirmiers. Cette norme générale, hautement recommandée dans la pratique, s'applique à toutes les personnes souffrant de douleur chronique ou aiguë.

OBJECTIFS : Évaluer l'état de l'évaluation de la douleur et déterminer les améliorations nécessaires dans 12 foyers pour personnes âgées d'une ville allemande.

MÉTHODOLOGIE : Dans la présente étude, les auteurs ont utilisé une méthodologie a posteriori (méthodologie du sondage). Les chercheurs ont analysé les politiques écrites pour évaluer systématiquement la douleur des résidents d'au moins 65 ans et ont mené un sondage auprès de 151 des 349 infirmières de 12 foyers pour personnes âgées entre septembre 2010 et avril 2011.

RÉSULTATS : Les plupart des foyers pour personnes âgées participants étaient dotés de directives écrites sur la gestion de la douleur, et la majorité des infirmières ont déclaré évaluer et réévaluer régulièrement la douleur. Cependant, de nombreux établissements ne possédaient pas d'outils d'observation pour les résidents ayant une grave atteinte cognitive et de calendriers de réévaluation écrite, ou ces mesures n'étaient pas uniformes. CONCLUSIONS : L'évaluation de la douleur semble faisable dans la plupart des foyers pour personnes âgées d'Allemagne. Cependant, l'absence ou la non-uniformité des calendriers de réévaluation démontre que les directives sur la gestion de la douleur devraient inclure un calendrier détaillé et explicite pour répondre aux besoins hétérogènes des habitants de foyers pour personnes âgées. Pour ceux ayant une importante atteinte cognitive, il est essentiel de concevoir des outils d'évaluation faciles à utiliser, qui indiquent clairement la présence ou l'absence de douleur.

assessment of pain in a manner that maximizes consistency across assessors and circumstances (12).

In addition to resident-related barriers to pain assessment, there are also obstacles in the organizational setting to overcome. NHs are characteristically slow to innovate due to high turnover rates, heavy workloads, varied training levels with a high proportion of low-wage workers among staff members, inconsistent regulatory practices and poor to no financial incentives to improve care (13). Moreover, wellintended recommendations may simply be impractical to implement (13). Studies investigating pain management in NHs reveal substantial gaps between current best practice and actual practice $(5,14-18)$. They reported omission of regular pain assessment (19), absence of written pain policies, absence of protocols to be used daily or weekly, and a lack of standardized pain assessment tools for cognitively intact residents, but especially for cognitively impaired residents $(5,16-18)$.

Pain management guidelines to be applied in nursing homes have been released by many expert associations in various countries

Paracelsus Medical University Salzburg, Institute of Nursing Science and Practice, Salzburg, Austria

Correspondence: Univ-Professor Dr Dr hc Jürgen Osterbrink, Paracelsus Medical University, Institute of Nursing Science and Practice,

Strubergasse 21, 5020 Salzburg, Austria. Telephone 43-662-2420-80300, fax 43-662-2420-80009,

e-mail juergen.osterbrink@pmu.ac.at 
TABLE 1

Requirements of the German national Expert Standard for Pain Management in Nursing and international guidelines with regard to pain assessment

\begin{tabular}{ll}
\hline $\begin{array}{l}\text { Recommendations of the German national Expert Standard for Pain } \\
\text { Management in Nursing (24) with regard to pain assessment* }\end{array}$ & $\begin{array}{l}\text { Corresponding recommendations in relevant international guidelines } \\
\text { for nursing homes }\end{array}$ \\
\hline
\end{tabular}

Requirement of initial pain assessment on admission

'At the start of the nursing contract, the nursing staff determines whether the patient/ resident has pain or pain-related problems. ...

Whenever pain or pain-related problems have been identified, systematic pain assessment takes place using adequate assessment tools.... One basic part of the pain assessment is the measurement of pain intensity via standardised scales... Also, the determination of pain localisation is always an integral part of pain assessment....Further parts of pain assessment depend on the target group and the individual situation.'

Requirement of regular reassessment for the duration of resident's stay

'Assessment of pain intensity and pain-related problems will be reviewed both at rest and on movement at regular intervals....Monitoring is the precondition for the evaluation of pain treatment....'

'In case no pain or pain-related problems were identified, assessment will be reviewed at individually defined intervals.'

\section{Requirement for provision of pain assessment tools}

'The healthcare facility provides assessment tools...for pain which are appropriate to the target group....'

'The availability of a selection of tools is a major prerequisite for systematic pain management. Such assessment tools are the visual analogue scale (VAS), the numeric rating scale (NRS), the verbal rating scale (VRS), and the pain faces scales....In selecting these tools, the cognitive ability and preferences of the patients/residents needs to be taken into consideration. For nonverbal patients/ residents, specific observational pain scales must be available.'

\section{Requirement for documentation of pain assessment}

'The healthcare facility provides...documentation tools for pain assessment which are appropriate to the target group....

'Policies for timely and complete documentation that covers all pain-related information have to be adopted. Such tools can be, for example, nursing records, pain diary and pain protocol.'

'All residents will have pain assessed... within 24 hours of admission....'(20)

'Evaluate the patient for pain upon the patient's admission to an LTC facility.' (23)

'All residents are screened for pain and assessed when pain is present.'

'All vulnerable elders should be screened for chronic pain during the initial evaluation period.' (21)

'All residents will have pain assessed...no less frequently than once a week.' (20)

'Every patient should be regularly and systematically evaluated for pain. ... at each quarterly and annual review; whenever a patient has an acute illness, injury or experiences a decline in function or a change in mood or cognition; whenever a patient exhibits unexpected social withdrawal or signs of depression; whenever vital signs are obtained; at least daily, for patients with a known painful condition; and before and after administration of as-needed analgesic medication.' (23)

'All residents are reassessed at intervals based on residents' needs, to determine residents' response to care and services and to plan for continued care and services or discharge.' (22)

'If pain is not identified during assessment on admission to residential care, it is recommended that the issue of pain identification is raised again: In the event of significant change in resident's condition; at any time that pain is suspected; every three months....Both at rest and movement-based (for example, during transfers) periods should be included in the assessment protocol when observational pain measures are undertaken.' (21)

'All residents will have pain assessed using a clinically appropriate and validated tool....' (20)

'The use of a standardized assessment tool that has been found to be valid and reliable with older adults is important....Staff members have selected a pain assessment method appropriate for each patient's cognitive level.'(23)

'Target indicators for pain management practice:...standardized facility assessment tool for cognitively intact and impaired residents, standardized facility pain scale...' (21)

'Assessment findings from each clinical discipline are documented in the resident's record and are readily available to those responsible for the resident's care and services.' (22)

'Document ongoing pain assessment.'(23)

'Target indicators for pain management practice:....standardized pain documentation flow sheet...' (21)

${ }^{*}$ Direct quotations, translated from German to English by the authors. ${ }^{\dagger}$ Direct quotations

(8,20-23). Although still not known by all nurses in Germany, a national evidence-based Expert Standard for Pain Management in Nursing was published for the first time in 2004, and is applicable to all types of health care facilities including nursing homes (24). The Expert Standard is not anchored in the law and, thus, breaches against it cannot be traced. However, it provides the potential for external adjusters to reveal carelessness by nurses. Additionally, it is explicitly recommended by governmental authorities, health care associations and professional care institutions. The recommendations of the Expert Standard for Pain Management share equivalent features with guidelines from other countries (Table 1). Briefly, the key principles of pain assessment are as follows: complete documentation of all pain-related information; use of an initial pain measure on admission followed by regular reassessments during the stay; and use of standardized scales for self-report and observational pain tools for residents with cognitive impairment.

The evaluation of actual practice compared with current best practice helps to identify the feasibility of the current recommendations and existing challenges yet to be resolved, including potential optimization. Thus, the aim of the present study was to compare the status quo of the assessment of pain (acute and/or chronic) with the requirements described in the German national Expert Standard for Pain Management in Nursing in NHs.

Design

\section{METHODS}

The present study, using an ex-post-facto design, is part of the German project Action Alliance Pain-free City Muenster (25), which 
investigates pain management in several health care settings (hospitals, NHs, outpatient nursing services, hospices, primary care and pain clinics) with the aim of improving pain management in these settings. In the $\mathrm{NH}$ research component, the initial data collection and analysis will be followed by a complex intervention developed on the basis of the identified gaps between current practice and the Expert Standard. A second data collection will enable a pre-post comparison, the results of which will be published separately. Data from the first data collection regarding pain assessment in the $\mathrm{NH}$ component were used in the present study.

\section{Sample}

The sample for the present study was drawn from voluntarily participating NHs in the city of Muenster and their nursing staff. All $32 \mathrm{NHs}$ listed by the Muenster health authorities were invited to participate in the study. Facilities with residents primarily affected by psychiatric conditions other than dementia were excluded because pain management in these circumstances must meet special requirements that were not the focus of the current research.

Efforts were made to include all registered nurses (three years of nursing education, according to European Union regulations) and nurse assistants (one year of nursing education) working in the $\mathrm{NHs}$, to achieve an exhaustive survey $(n=349)$. Assistants with no or $<1$ year of education were excluded from the study. Participation in the study was voluntary; thus, the study used a convenience sample.

\section{Data collection}

Collection of written policies: To obtain information on the existing policies and procedures of pain management in the NHs, the managers of the facilities were asked to submit, with the aid of a checklist, all available documents on pain management. The checklist asked whether documentation forms, procedures, guidelines, institutional or in-house standards, or other written instructions on pain management were available.

Online questionnaire for nurses: Selected aspects of pain management were assessed by questioning the nursing staff. All of the nursing staff who registered for the study were given an anonymous access code, which allowed them to log in to the survey portal. The questionnaires were self-administered and all answers were completed online (using a computer-assisted self-interview). Data collection in the 12 NHs occurred between September 2010 and April 2011, over a period of four weeks in each $\mathrm{NH}$.

The online interview consisted of a standardized questionnaire with 39 questions, 12 of which were filter questions. Filter questions were posed only when the previous question had been answered positively or negatively in the given context. The leading criterion in the development of the questionnaire was the national Expert Standard for Pain Management in Nursing (24) of the German Network for Quality Development in Nursing. The five main sections of the Expert Standard are pain assessment, pharmacological and nonpharmacological pain therapy, prophylaxis/treatment for side effects of pain therapy and patient/resident education. The questionnaire also asked about the existence of written policies for pain management, the quality of communication between the nursing staff and external attending physicians, the quality of the in-house pain management, the existence of continuing education offered and completed within the facility, and sociodemographic data of the nursing staff.

Apart from the demographic and professional data used to describe the sample, only questions regarding pain assessment were included in the current analysis. These questions focused on four topics within pain assessment (Table 1): initial pain assessment; reassessment of pain; pain assessment tools; and documentation of pain assessment. Concerning initial pain assessment, nurses were asked whether residents' pain status was assessed at first admission and/or return from hospital, and what questions were used during this assessment. With regard to reassessment, the survey inquired whether pain assessment was repeated regularly and whether pain intensity was assessed during the course of the stay for both pain at rest and pain on movement. For the section on pain assessment tools, the questions centred on the type and actual use of scales to measure pain intensity for self-reports as well as for observational assessment. With regard to documentation, the nurses were queried about whether the assessment of pain was noted in the nursing records, whether the intensity of pain was recorded in writing and, if not, in what form pain was documented (see the questionnaire excerpts in Appendix 1).

The questionnaire development was based on discussions among an expert committee consisting of German and Austrian scientists from various disciplines (nursing science, geriatrics, health sciences and sociology). Following the internal discussion of the project group, the questionnaires were presented and evaluated by two independent and unaffiliated nurse specialists. Subsequently, the questionnaire was piloted in an NH outside of Muenster (which was not included in the present study) for empirical testing. This preliminary testing focused on the following aspects: comprehensibility and content validity of the questionnaire, determined by face-to-face interviews with the nurses; technical feasibility of the computerassisted self-interview; and how long the questionnaire took to complete. Following preliminary testing, the items in the questionnaire were reviewed by the expert committee and adapted accordingly. In particular, one question was excluded completely because of redundant content, several other questions were revised due to ambiguity in the answer options and one other question was reworded to clarify its semantic meaning.

\section{Ethical considerations and data protection}

The ethics committee of the medical faculty of the local university (University of Muenster Ethics Committee, Medical Faculty, Westfaelische Wilhelms University of Muenster, Muenster, Germany) approved the research project. All respondents provided written informed consent after being assured anonymity, voluntary participation and their right to withdraw from the study at any time without repercussions.

\section{Data analysis}

After pseudonymization, the answers were stored electronically and imported into SPSS version 18.0 (IBM Corporation, USA) for analysis. Descriptive statistical analyses were applied to all data, whereupon univariate analyses were used exclusively. In addition to tabular and graphic charts of distribution frequency, the analyses included commonly used statistical values for central tendency, dispersion and distribution, depending on the variable of interest. The method of multiple dichotomies was used to analyze multiple answers.

Internal documents on pain management were checked to discover the extent to which written policies and documentation forms for pain assessment were available. The written policies were examined, focussing on procedures for pain assessment and documentation. By these means, information was collected on the regulations applied in these $\mathrm{NHs}$ as well as the special needs of the residents. The report forms were examined to verify whether pain could be documented in the initial history taking and/or during the stay in the nursing home, precisely what information should be recorded (pain, pain-related problems, the site and severity of the pain, differentiation between pain at rest and pain on movement) and what scales were used for pain assessment.

In the Results section, the recommendations of the Expert Standard in each section will be presented and subsequently compared with the status quo in the NHs, as disclosed by the nurses' statements and the provided written policies of the facilities.

\section{Sample}

\section{RESULTS}

Of the $32 \mathrm{NHs}$ invited, 15 facilities expressed willingness to participate. One $\mathrm{NH}$ was excluded because its residents had primary mental disorders other than dementia. One $\mathrm{NH}$ withdrew before data 
collection for reasons unrelated to the research project. Another NH had to be excluded during data cleansing because systematic response bias was suspected. Therefore, the convenience sample consisted of $12 \mathrm{NHs}$. Ten NHs were run by nongovernmental organizations (eg, church, social services), one by the community and one by a private company. The $12 \mathrm{NHs}$ had 52 to 171 residential beds (median 81 beds), employed between 16 and 62 registered nurses (median 20), zero to 24 nurse assistants with one year of nursing education (median three) and two to 34 assistants with no or $<1$ year of formal nursing education (median 13; excluded from the study).

At the start of the project, these $12 \mathrm{NHs}$ registered 349 members of nursing staff (registered nurses and nurse assistants with one year of education), 151 of whom participated in the survey, resulting in a response rate of $43 \%$. From each nursing home, between six and 28 members of staff participated. Among the 151 nurses, there were 122 women (81\%).

Nurses had worked between one and 37 years, including the time of training, in their profession and one-half had worked for $\leq 11$ years. On average, 148 nurses for whom sociodemographic data were available had been working in the field for 13 years. The majority $(72 \%)$ of the nursing staff were specialized geriatric nurses. Eleven (7\%) of the 151 were geriatric nurse assistants.

\section{Initial pain assessment}

The Expert Standard specifies that at the start of the nursing contract, nursing staff should determine whether the admitted individual has pain or pain-related problems (Table 1). According to the internal documents submitted, nine of the $12 \mathrm{NHs}$ had documentation forms for initial pain assessment. In the present study, 50\% of nurses stated that they 'always' ask the residents about pain on admission, $32 \%$ do it 'usually', 15\% 'sometimes', and only 3\% 'rarely' or 'never'.

Furthermore, the Expert Standard describes that whenever pain or pain-related problems have been identified, care providers should use a systematic pain assessment that involves the basic determination of the intensity and location of the pain (Table 1). Both aspects were always mentioned in the nine documentation forms submitted to the research team. According to the answers in the present sample, nearly all of the nursing staff (98\%) who asked residents about pain on admission also inquired about the location of pain. Almost three-quarters (110 of 147 valid responses) asked about its intensity and more than one-half (86 of 147 valid responses) asked about the frequency. In summary, the criteria of the Expert Standard on initial pain assessment have largely been met in this sample.

\section{Reassessment of pain}

The Expert Standard requires that pain assessment should be reviewed and updated at regular intervals on a case-by-case basis and that this should apply equally to residents with and without pain or pain-related problems as determined in the initial assessment (Table 1). Slightly less than three-quarters of the nursing staff $(n=102)$ who had asked residents about pain on admission stated that they reassessed pain regularly; $67 \%$ of all nursing staff (including those who did not ask about pain on admission) reassessed pain during the residents' stay.

The Expert Standard also stipulates that pain intensity should be assessed both at rest and on movement. Pain intensity was included in all eight documentation forms submitted for reassessment, but only four differentiated between pain at rest and pain on movement. In this respect, there appears to be a clear need for improvement in many facilities. According to the answers given, nearly all nursing staff $(96 \%)$ asked about pain intensity at rest at least sometimes. Slightly less than one-half $(46 \%)$ asked about pain intensity at rest at least once per shift. Pain on movement was asked about more often than pain at rest. Nearly all nursing staff (99\%) asked at least sometimes about pain on movement and $56 \%$ did so once or more per shift.

Only six of 12 facilities had written policies on a reassessment schedule that indicated how often and in what instances pain should be reviewed during the stay in the nursing home. The existing policies were extremely diverse and had very little in common. For instance, one facility simply indicated that the responsible nurse should determine the schedule of reassessment. Another facility gave a complex description of the occasions in which pain should be reassessed (eg, in crises and/or changes in health status) and defined the precise intervals at which the assessment should be performed.

In summary, the requirements of the Expert Standard on reassessment of pain have been partially met by the included nursing homes. A need for optimization could be identified with regard to the lack of differentiation between pain at rest and pain on movement, the percentage of staff carrying out reassessments and the lack of written policies on reassessment schedules in many facilities.

\section{Pain assessment tools}

According to the Expert Standard, health care facilities are required to provide a selection of tools for self-report and specific observational tools for nonverbal residents. In selecting these tools, the cognitive ability and preferences of the residents need to be taken into consideration (Table 1). In the current sample, pain assessment tools were provided in 10 of $12 \mathrm{NHs}$, and 130 of 150 nurses (87\%) stated by self-report that they used a scale for assessing pain intensity. According to the in-house documents, the numerical rating scale (NRS) was provided by all $10 \mathrm{NHs}$ that used scales. Alternative scales were provided in only three NHs: the Faces Pain Scale (FPS) in all three of these facilities, as well as the verbal rating scale (VRS) in one of them. In accordance with this finding, the answers from the members of the nursing staff who used scales showed that the NRS was most commonly used (65\%), followed by the FPS (56\%) and then the VRS (15\%) (Figure 1). The visual analogue scale was not provided by any of the $\mathrm{NHs}$ and, therefore, was used by only a handful $(6 \%)$ of the nursing staff (Figure 1$)$.

With respect to self-report, it can, therefore, be established that most - but not all - NHs use appropriate tools. However, the recommendation that a selection of suitable tools be provided is not sufficiently well implemented.

Observational pain tools, which are required for cognitively impaired residents without the ability to self-report, were provided in only six of the $12 \mathrm{NHs}$. The majority of the nursing staff stated that either they are not familiar with the tools mentioned (50\%) or that no observational pain tool is used in their particular nursing home $(17 \%)$ (Figure 1). In the present sample, L' échelle Comportementale pour Personnes Agées (ECPA) (26) was the best known and most frequently used scale for observational assessment. It was mentioned by slightly more than one-quarter of the nursing staff who used a scale to assess pain (Figure 1). The Pain Assessment in Advanced Dementia Scale, German version (27) was barely known in this sample, with the Zurich Observational Pain Assessment (ZOPA) (28) and the Doloplus-2 (29) not being mentioned at all. Two NHs used their own behavioural checklists for pain assessment.

Thus, observational pain tools were less well known and less frequently used by the nursing staff than self-report scales. A large proportion (41\%) of the 130 nurses who indicated using a pain assessment scale were not familiar with observational pain tools.

In summary, it can be concluded that the requirements for observational pain assessment tools are met in only six of the $12 \mathrm{NHs}$. There is a great deal of room for improvement in a large proportion of the facilities studied.

\section{Documentation of pain assessment}

The Expert Standard requires that the health care facility provide population-specific tools for documenting pain as well as rules for the timely and complete recording of all pain-related information. This can be in the form of entries in the nursing records, pain diaries or pain course reports (Table 1). According to the in-house documents, written policies for the documentation of pain were available in six NHs; however, they were absent in the remaining six facilities. In $10 \mathrm{NHs}$, the submitted documents contained documentation forms for the initial pain assessment, for reassessment or both. According to the answers provided, $94 \%$ of the nursing staff who asked residents about 


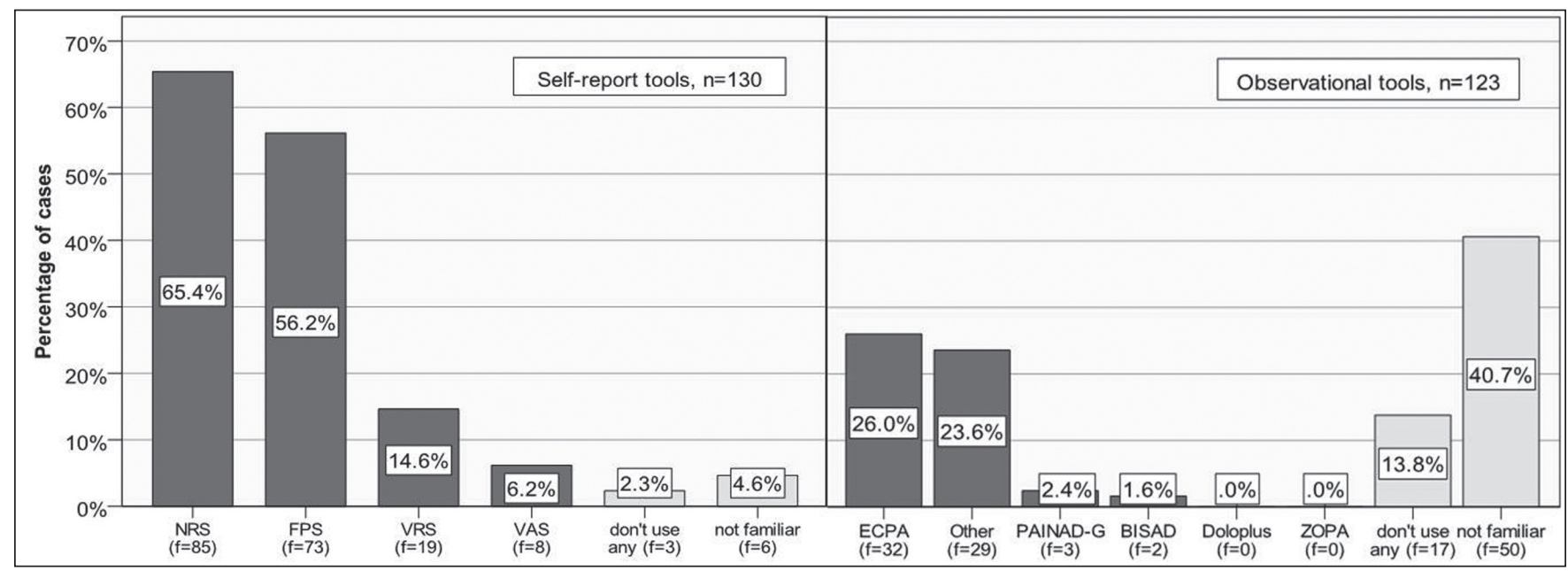

Figure 1) Answers from the nursing staff regarding which scales they use for self-report (left) and observational assessment (right) (more than one answer possible). Total, $n=151$ (100\%); valid for self-report, $n=130$ (86.1\%); valid for observational tools, $n=123$ (81.5\%). BISAD German abbreviation of L'échelle Comportementale pour Personnes Agées (ECPA); $f$ Frequency; FPS Faces Pain Scale; NRS Numerical rating scale; PAINAD-G Pain Assessment in Advanced Dementia Scale, German version; VAS Visual analogue scale; VRS Verbal rating scale; ZOPA Zurich Observation Pain Assessment

\section{TABLE 2}

\section{Core findings of the status quo of pain assessment in 12 nursing homes (NHs) in Germany}

\begin{abstract}
Dimension of the Expert Standard Nurses' answers
Initial pain assessment $\quad 50 \%$ of the nurses always assess pain on admission,

$81 \%$ at least usually

Reassessment of pain

Pain assessment tools

Tools for self-assessment

Observational tools

Documentation of pain assessment

$87 \%$ of nurses use a pain assessment tool

FPS) for self-assessment (Doloplus, ECPA, BISAD, PAINAD-G, ZOPA)

$94 \%$ of nurses who assessed pain documented it

pain at admission or return from hospital stated that they documented the pain assessment, and $93 \%$ documented pain intensity.

In summary, the requirement of the Expert Standard on the documentation of pain assessment is largely met by the included facilities, but written policies on this subject are lacking in one-half of the NHs. Documentation forms did not distinguish between initial assessment and reassessment in all facilities. Table 2 summarizes the core findings of the survey.
\end{abstract}

$67 \%$ of all nursing staff reassessed pain during the stay

93\% use one of the four predefined tools (NRS, VAS, VRS,

$46 \%$ use one of the six predefinedobservational pain tools
Written policies in the 12 facilities

Nine $\mathrm{NHs}$ provided documentation forms for initial pain assessment

Six NHs had written policies on pain reassessment

$10 \mathrm{NHs}$ provided pain assessment tools

All $10 \mathrm{NHs}$ provided tools for self-assessment

Six NHs provided observational pain tools

$10 \mathrm{NHs}$ provided documentation forms

Six NHs provided written policies for pain assessment

BISAD German version of L'échelle Comportementale pour Personnes Agées (ECPA); PAINAD-G Pain Assessment in Advanced Dementia Scale, German version; FPS Faces Pain Scale; NRS Numerical rating scale; VAS Visual analogue scale; VRS Verbal rating scale; ZOPA Zurich Observational Pain Assessment

\section{DISCUSSION}

The current study investigated the adherence of $12 \mathrm{NHs}$ in the German city of Muenster to the requirements of the German national Expert Standard for Pain Management in Nursing. The results indicate that pain assessment is already an inherent part of nursing care in most of the NHs included in the sample. Documentation forms for recording pain are available in most of the $\mathrm{NHs}$ and, according to the information they provided, three-quarters of the nursing staff stated that they usually or always asked the residents about pain on admission. More than $90 \%$ of the respondents probed the residents about pain at least sometimes during the stay. However, the requirement of the Expert Standard to assess pain intensity both at rest and on movement was not implemented consistently in the majority of the NHs.

With respect to assessment tools, most facilities provided the NRS, a tool suitable and recommended for older persons with no or mild to moderate cognitive impairment $(8,10,21,24,30,31)$. Still, the requirement of the Expert Standard to provide a selection of suitable tools was not fulfilled in three-quarters of the included facilities. Suitable assessment tools for self-report, such as the VRS and the FPS $(8,10,32)$, are available in German and could be implemented. Nonetheless, the use of assessment tools is regulated by the respective in-house guidelines, which only provides the NRS. Using only one standard scale for the entire facility is simpler and, from a qualitymanagement point of view, less prone to error than selecting a suitable assessment tool for each individual resident. However, the notion that only one tool is an effective way to deal with this issue is faulty at best $(33,34)$.

Major challenges yet to be resolved were found in two aspects. One major deficit has been identified with regard to observational pain tools for residents with severe cognitive impairment, which are recommended by the German Expert Standard (24) as well as by international guidelines $(8,30,31,34)$. These tools were absent in the majority of facilities and hardly known by the nurses. There are currently three validated observational pain scales available in German: the Pain Assessment in Advanced Dementia Scale, German version (11); the ECPA (26,35); and the ZOPA. The ZOPA is intended solely for patients with reduced consciousness and impaired cognitive function, and is validated for use in hospitals (28), but not in NHs. The Pain Assessment Checklist for Seniors with Limited Ability to Communicate and the Doloplus-2, which are rated in international publications to be among the observational scales with the greatest reliability and validity $(8,36-38)$, are not yet available as validated German translations. Currently, the Doloplus-2 is available as a nonvalidated translation that has been tested in NHs (35). The ECPA was the best-known and most frequently used scale for observational 
assessment in the present sample, but was still used by only onequarter of the nurses.

A possible reason for shortcomings in the implementation of observational pain tools is the fact that these tools are still under development and have, compared with self-report scales, limited psychometric qualities (36). Nurses may be concerned that these assessment tools lack specificity to pain (39). Additionally, the application of the instruments may be too time consuming in today's busy work environments (39). Concerning the pain assessment scales, the lack of knowledge regarding appropriate cut-off values, which are designed to determine when to initiate an intervention, undermines the clinical feasibility of these tools.

The second remarkable deficit concerns the absence or inconsistency of regulations on a reassessment schedule (ie, how often and at what instances assessment of pain should be reviewed during the stay in the NH). On this topic, the Expert Standard only states that reassessment has to be performed at regular intervals on a case-by-case basis without providing further orientation (Table 1). Lack of orientation may have contributed to the absence or inconsistency of these regulations. In the meantime, a German guideline including detailed recommendations for reassessment in NHs is under development (40).

\section{Strengths and limitations of the study}

Data regarding the application of pain guidelines in long-term care are scant (41). To our knowledge, the present study is one of the few that have investigated adherence of $\mathrm{NHs}$ to evidence-based guidelines with respect to pain management. The few existing studies including pain assessment in long-term care have predominantly been conducted in the United States, and several were performed in the United Kingdom. The present study allows, for the first time, an international glimpse into the German situation. The present study from Germany is in accordance with the studies from the United States and the United Kingdom revealing gaps between current best practice and actual practice. Additionally, it indicates a need for improvement regarding the application of assessment tools and reassessment schedules individually tailored to the heterogenic needs of nursing home residents.

There are several limitations to the present study. First, because a convenience sample was used, the sample was not necessarily representative. Given that an exhaustive survey was intended, the response rate of $43 \%$ was relatively low. A reasonable number of nonresponders were anticipated as a result of high workloads and the subsequent lack of time inherent to the nursing profession. Some nonresponses could also be due to the failure to see participation as beneficial. In this respect, it must be acknowledged that study participation occurred on a voluntary basis, which may limit its representativeness. However, due to issues of social desirability and to avoid suspicion in the context of conducting research on nurses' pain management behaviour, we opted for a voluntary sampling procedure to obtain more valid answers. In other studies utilizing voluntary responses of staff members, the response rates were similar $(5,17,42)$. We assume that the available responses of the nursing staff combined with the evaluation of in-house documentation still provide indepth information about the implementation of pain management in each $\mathrm{NH}$.

It may not be possible to extrapolate the present results to other countries because of differences in national guidelines, education of nursing staff and work organization at the facilities, along with other possible general differences.

Finally, the Expert Standard is valid only in Germany. NHs in other countries follow different guidelines. Still, the recommendations of the German Expert Standard comprise fundamental aspects of pain assessment that are shared by most other pain management guidelines for hospitalized or residential care patients (Table 1).

\section{CONCLUSION}

Adherence of $\mathrm{NHs}$ to pain management guidelines with respect to pain assessment has rarely been evaluated. The current study is likely the first to deal with this topic in detail and provide insight into the German situation. Pain assessment was found to be an inherent part of care in most facilities included; however, gaps between the actual practice and evidence-based standard were observed in several aspects. Although assessment tools were provided by most facilities and used by most nurses, observational tools for nonverbal and cognitively impaired residents have yet to be implemented in many NHs. Finally, the current study highlights the requirement for the development of a detailed reassessment schedule that considers the diverse needs of $\mathrm{NH}$ residents in Germany as well as globally.

DISCLOSURES: The authors have no conflicts of interest to declare. The sponsors had no influence on the scientific collection and evaluation of the project data.

ACKNOWLEDGEMENTS: The authors thank the following for their technical and theoretical scientific support: Marco Hufnagel, Stephanie Hemling (project coordination), Wolfgang Aschauer, Martin Weichbold (statistical analysis), Erika Sirsch, Nadja Nestler, Andre Ewers (advice and critical review of the study design), Daniel Zenz (information technology), Cornelia Krüger (design and analysis of the study, critical review of the manuscript) and Nadine Schüssler (critical review of the manuscript). The authors also thank all the residents and nursing staff of the nursing homes who participated in the study.

FUNDING: The study was sponsored, in part, by Mundipharma GmbH, Limburg, Germany. Additional funding was provided by the Province of Salzburg, Austria, and the City of Muenster, Germany.

\section{APPENDIX 1}

Excerpt from the questionnaire (translated from German by the authors): Questions from the nursing staff questionnaire which were included in the current analysis.

(The questions are not shown in the order in which they appeared in the questionnaire but have been organized according to the topics addressed by this analysis. The research identification codes we used are given with each question.)

\section{Initial pain assessment}

- AH_PF_1: Do you ask the residents about pain when they are admitted into the nursing home (on the first admission and/or return from hospital)?

$\square$ Always $\square$ Usually $\square$ Sometimes $\square$ Rarely $\square$ Never

- FILTER, if the response to AH_PF_1 is 'always', 'usually', 'sometimes', 'rarely'

AH_PF_1a: What do you ask about on admission and/or return from hospital? (More than one answer is possible.)

$\square$ About the intensity of the pain

$\square$ About the frequency of the pain

$\square$ About the location of the pain

$\square$ Other (please specify):

\section{Reassessment of pain}

- FILTER, if the response to AH_PF_1 is 'always', 'usually', 'sometimes', 'rarely'

AH_PF_1b_01: Is the documented pain assessment reviewed regularly?

$\square$ Yes $\square$ No $\square$ I don't know

- AH_PF_2: Do you ask the residents regularly about the intensity of their pain during the course of their stay in the nursing home?

Pain assessment tools

- AH_PF_3: In your nursing home, do you use a scale to measure the intensity of pain? $\square$ Yes $\square$ No $\square$ I don't know

- FILTER, if the response to AH_PF_3 is 'yes' AH_PF_3a: Which self-report scale do you use for the residents to assess their own pain? (More than one answer is possible.) 


\section{APPENDIX 1 - CONTINUED}

Numerical rating scale (NRS)

$\square$ Visual analogue scale (VAS)

$\square$ Verbal rating scale (VRS)

$\square$ Faces Pain Scale

$\square$ We don't use any scales for self-report

$\square$ I'm not familiar with the scales mentioned above

- FILTER, if the response to AH_PF_3 is 'yes'

\begin{tabular}{lcccc}
\hline & Never & Sometimes & $\begin{array}{c}\text { Once per } \\
\text { shift }\end{array}$ & $\begin{array}{c}\text { Several times } \\
\text { per shift }\end{array}$ \\
\hline About pain at rest & $\square$ & $\square$ & $\square$ & $\square$ \\
\hline $\begin{array}{l}\text { About pain on } \\
\text { movement }\end{array}$ & $\square$ & $\square$ & $\square$ & $\square$ \\
\hline
\end{tabular}

AH_PF_3b: Which scales do you use for observational assessment of the resident's pain? (More than one answer is possible.)
$\square$ Doloplus
$\square$ ECPA
$\square$ BISAD
$\square$ PAINAD-G
$\square$ ZOPA

\section{REFERENCES}

1. Sawyer P, Lillis JP, Bodner EV, Allman RM. Substantial daily pain among nursing home residents. J Am Med Dir Assoc 2007;8:158-65.

2. Ferrell BA, Ferrell BR, Rivera L. Pain in cognitively impaired nursing home patients. J Pain Symptom Manage 1995;10:591-8.

3. Cramer GW, Galer BS, Mendelson MA, Thompson GD. A drug use evaluation of selected opioid and nonopioid analgesics in the nursing facility setting. J Am Geriatr Soc 2000;48:398-404.

4. Takai Y, Yamamoto-Mitani N, Okamoto Y, Koyama K, Honda A. Literature review of pain prevalence among older residents of nursing homes. Pain Manag Nurs 2010;11:209-23.

5. Allcock N, McGarry J, Elkan R. Management of pain in older people within the nursing home: A preliminary study. Health Soc Care Community 2002;10:464-71.

6. Fox P, Raina P, Jadad A. Prevalence and treatment of pain in older adults in nursing homes and other long-term care institutions: A systematic review. Can Med Assoc J 1999;160.

7. DNQP. [Expert Standard for Pain Management in Nursing]. Osnabrück, Germany: German Network for Quality Development in Nursing, 2005.

8. Hadjistavropoulos T, Herr K, Turk DC, et al. An interdisciplinary expert consensus statement on assessment of pain in older persons. Clin J Pain 2007;23:S1-43.

9. RKI, GFSO. Altersdemenz. Robert Koch Institute, German Federal Statistical Office; 2005 <http://dgk.de/fileadmin/user_upload/AIW/ pdf/RKI_Altersdemenz.pdf> (Accessed December 13, 2012).

10. Herr K. Pain assessment strategies in older patients. J Pain 2011;12:S3-S13.

11. Basler HD, Hüger D, Kunz M, Lukas A, Nikolaus T, Schuler MS. [Assessment of pain in advanced dementia. Construct validity of the German PAINAD]. Schmerz 2006;6:519-26.

12. Hadjistavropoulos T, Fitzgerald TD, Marchildon GP. Practice guidelines for assessing pain in older persons with dementia residing in long-term care facilities. Physiother Can 2010;62:104-13.

13. Rahman AN, Applebaum RA, Schnelle JF, Simmons SF Translating research into practice in nursing homes: Can we close the gap? Gerontologist 2012;52:597-606.

14. Jablonski A, Ersek M. Nursing home staff adherence to evidencebased pain management practices. J Gerontol Nurs 2009;35:28-34.

15. Decker SA, Culp KR, Cacchione PZ. Evaluation of musculoskeletal pain management practices in rural nursing homes compared with evidence-based criteria. Pain Manag Nurs 2009;10:58-64.

16. Weissman DE, Griffie J, Muchka S, Matson S. Building an institutional commitment to pain management in long-term care facilities. J Pain Symptom Manage 2000;20:35-43.

17. Barry HE, Parsons C, Passmore AP, Hughes CM. An exploration of nursing home managers' knowledge of and attitudes towards the management of pain in residents with dementia. Int J Geriatr Psychiatry 2012;27:1258-66. $\square$ Other (please specify):

$\square$ We don't use any scales for observational assessment

$\square$ I'm not familiar with the scales mentioned above

Documentation of pain

- FILTER, if the response to AH_PF_1 is 'always', 'usually', 'sometimes', 'rarely'

AH_PF_1b: Is the assessment of pain recorded in the nursing records?

$\square$ Yes $\square$ No $\square$ I don't know

- AH_PF_4: Is the intensity of the resident's pain recorded in writing?

$\square$ Yes $\square$ No

- FILTER, if the response to AH_PF_4 is 'yes'

AH_PF_4a: Where is the intensity of the pain documented?

(More than one answer is possible.)

$\square$ With the vital signs

$\square$ In the nursing record

$\square$ In the resident's pain diary

$\square$ On special forms

$\square$ I don't know where it's recorded

18. Keeney CE, Scharfenberger JA, O’Brien JG, Looney S, Pfeifer MP, Hermann CP. Initiating and sustaining a standardized pain management program in long-term care facilities. J Am Med Dir Assoc 2008;9:347-53.

19. Clark L, Jones K, Pennington K. Pain assessment practices with nursing home residents. West J Nurs Res 2004;26:733-50.

20. Hadjistavropoulos T, Marchildon GP, Fine PG, et al. Transforming long-term care pain management in North America: The policyclinical interface. Pain Med 2009;10:506-20.

21. APSOC. Pain in Residental Aged Care Facilities - Management Strategies. North Sydney: The Australian Pain Society, 2005.

22. Joint Commission International. Accreditation Standards for Long Term Care. Oak Brook: Joint Commission International, 2012.

23. American Medical Directions Association. Pain Management in the Long-Term Care Setting. Clinical Practice Guideline. Columbia: American Medical Directors Association, 2012.

24. DNQP. [Expert Standard for Pain Management in Nursing]. Osnabrück, Germany: German Network for Quality Development in Nursing (DNQP); 2004.

25. Osterbrink J, Ewers A, Nestler N, et al. [Health services research project "Action Alliance Pain-Free City Munster": Objectives and methods]. Schmerz 2010;24:613-20.

26. Morello R, Jean M, Alix M, Sellin-Peres D, Fermanian J. A scale to measure pain in non-verbally communicating older patients: The ECPA-2 study of its psychometric properties. Pain 2007;133:87-98.

27. Warden V, Hurley AC, Volicer L. Development and psychometric evaluation of the Pain Assessment in Advanced Dementia (PAINAD) scale. J Am Med Dir Assoc 2003;4:9-15.

28. Handel E, ed. Praxishandbuch ZOPA. Bern: Verlag Hans Huber, 2010.

29. Wary B, collectief Doloplus. Doloplus-2, une échelle pour évaluer la douleur. Soins Gérontologie 1999;19:25-7.

30. BPS, BGS. Guidance for the assessment of pain in older adults: A literature review. British Pain Society, British Geriatrics Society. Br J Nurs 2008;17:914-8.

31. RCP. The Assessment of Pain in Older People: National Guidelines. Concise Guidance to Good Practice Series No 8. London: Royal College of Physicians, 2007.

32. Horgas AL, Yoon SL. Pain management. In: Capezuti E, Zwicker D, Mezey M, T F, eds. Evidence-Based Geriatric Nursing Protocols for Best Practice. 3rd edn. New York: Springer Publishing Company, 2008:199-222.

33. Pasero C, McCaffery M. No self-report means no pain-intensity rating: Assessing pain in patients who cannot provide a report. Am J Nurs 2005;105:50-3.

34. Herr K, Coyne P, McCaffery M, Manworren R, Merkel S. Pain assessment in the patient unable to self-report. Position statement with clinical practice recommendations. Pain Manag Nurs 2011;12:230-50. 
35. Fischer T. [Development of a Pain Assessment Instrument for Persons with Severe Dementia]. Berlin: Charite; 2009 <www.diss. fu-berlin.de/diss/servlets/MCRFileNodeServlet/FUDISS_

derivate_000000005812/Dissertation_Abgabefassung.pdf?hosts=> (Accessed December 12, 2012).

36. Zwakhalen SM, Hamers JP, Berger MP. The psychometric quality and clinical usefulness of three pain assessment tools for elderly people with dementia. Pain 2006;126:210-20.

37. Corbett A, Husebo B, Malcangio M, et al. Assessment and treatment of pain in people with dementia. Nat Rev Neurol 2012;8:264-74.

38. Herr K, Bursch H, Ersek M, Miller LL, Swafford K. Use of painbehavioral assessment tools in the nursing home: Expert consensus recommendations for practice. J Gerontol Nurs 2010;36:18-29; quiz 30-1.
39. Liu JY, Briggs M, Closs J. Acceptability of Pain Behaviour Observational Methods (PBOMs) for use by nursing home staff. J Clin Nur 2011;20:2071-3.

40. Sirsch E, Schuler M, Fischer T, et al. [Pain assessment in elderly nursing home residents. Methods paper for the S3-guideline development]. Schmerz 2012;26:410-8.

41. Farless L, Ritchie C. Challenges of pain management in long-term care. Ann Longterm Care 2012;20:32-8.

42. Tarzian AJ, Hoffmann DE. Barriers to managing pain in the nursing home: findings from a statewide survey. J Am Med Dir Assoc 2005;6:S13-9. 


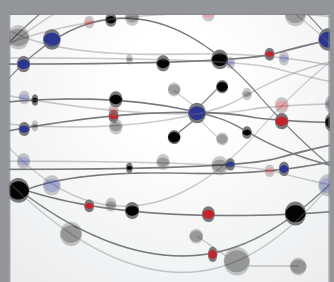

The Scientific World Journal
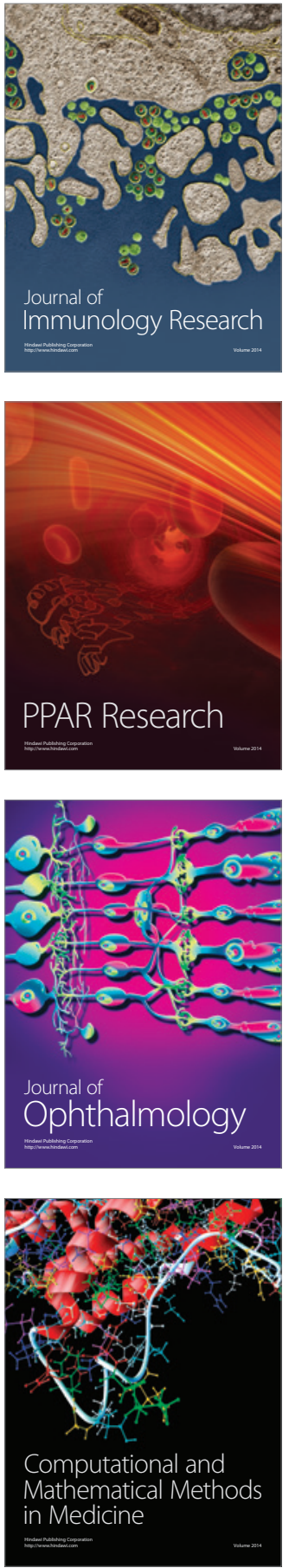

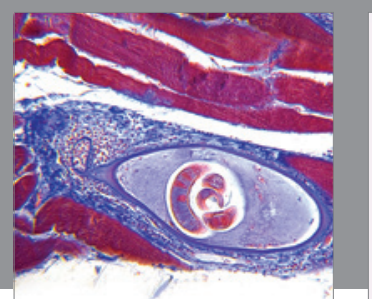

Gastroenterology Research and Practice

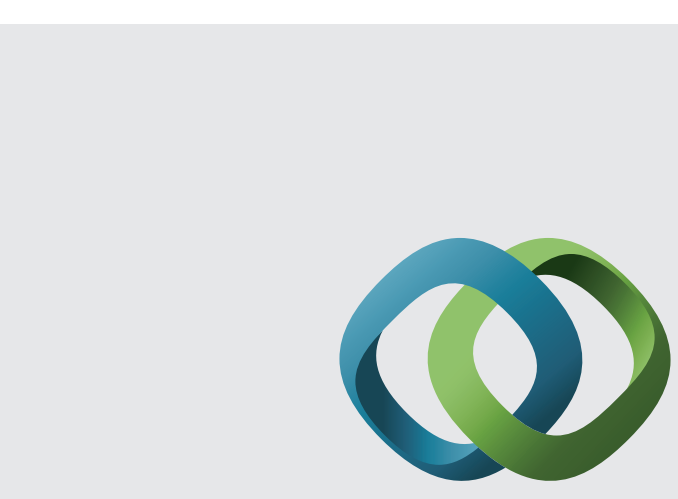

\section{Hindawi}

Submit your manuscripts at

http://www.hindawi.com
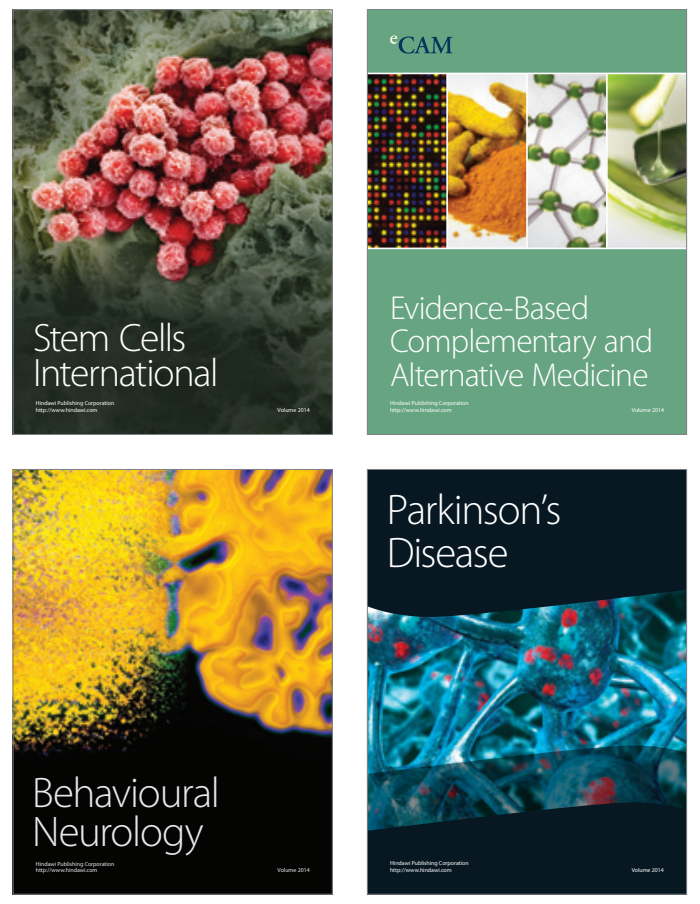
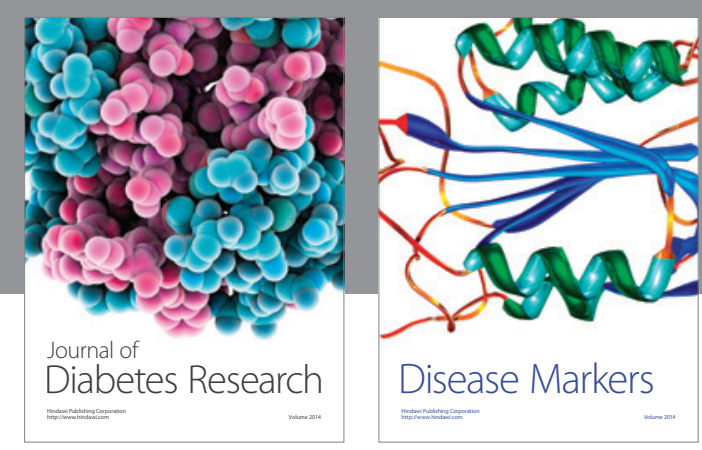

Disease Markers
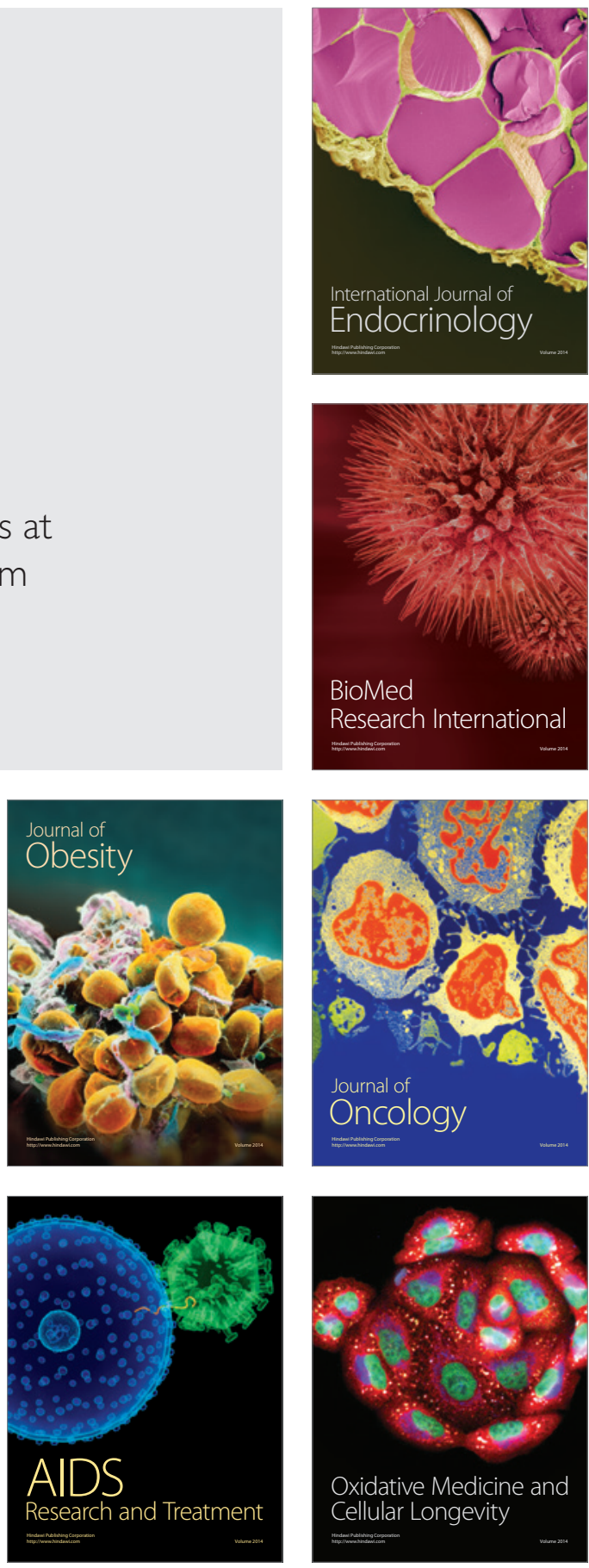